\title{
PRELIMINARY RECONSTRUCTION OF DIET AT A NEOLITHIC SITE IN VIETNAM USING STABLE ISOTOPE AND BA/SR ANALYSES
}

\author{
Nathan W. Bower ${ }^{1}$, Yuichiro Yasutomo ${ }^{1}$, Marc F. Oxenham ${ }^{2}$, Nguyen Lan Cuong ${ }^{3}$, Nguyen Kim Thy ${ }^{3}$ \\ ${ }^{1}$ Chemistry Department, Colorado College, Colorado Springs, CO 80903, ${ }^{2}$ School of Anthropology and Archaeology, Australian \\ National University, Canberra, ACT 0200, ${ }^{3}$ Institute of Archaeology, Hanoi, Socialist Republic of Vietnam
}

\begin{abstract}
In order to better evaluate the role plant exploitation played at a Neolithic site (Con Co Ngua, ceramic context dated to 5000 years BP) in Vietnam, we measured the $\delta^{13} C$ in apatite from human teeth at this site as well as from a nearby Metal Period site (Nui Nap), with a carbon date of 1670 years $B P$, where $\delta^{13} C$ and $\delta{ }^{15} N$ from collagen were also measured. Ba:Sr ratios at both sites were determined in order to estimate the importance of marine versus agricultural food sources. Results are consistent with incipient plant exploitation at Con Co Ngua, while dietary $C_{3}$ plants that might have included rice played a smaller role than at Nui Nap. Marine sources appear to be more significant at the earlier site.
\end{abstract}

\section{INTRODUCTION}

Vietnam is perhaps one of the least bioarchaeologically researched countries in Southeast Asia. While anatomically modern humans have resided in the region since at least 30,000 BP (Nguyen 1997), the earliest culturally distinct period is the Hoabinhian dating from between 18,000 and approximately $6000 \mathrm{BP}$. This period is characterized by foraging for a variety of vertebrates, shellfish and plants (Higham 1989). The Neolithic emerges from the Hoabinhian around $6000 \mathrm{BP}$ in the form of a number of archaeological cultures including the Da But. The Da But culture period lasted for at least 1700 years and is characterized by numerous shell middens containing polished lithics, simple ceramics and apparently domesticated pigs and buffalo (Bui Vinh 1991).

While Da But communities are considered to be sedentary foragers, the relative importance of marine compared to terrestrial foods in their diet is unclear (Oxenham et al. 2005). Further, given that the Da But is traditionally seen as representing the beginnings of the Neolithic in the region, is there evidence of an agricultural component to their diet? The chief aim of this study is to assess the relative importance of terrestrial verses marine foods in the Da But diet and to determine whether plant exploitation (perhaps in the form of plant cultivation) might have played an important dietary role.

Little in the way of stable isotopic work has been carried out in Southeast Asia. Exceptions include King and
Norr's (2006) isotopic study of temporal changes in the diet at Ban Chiang, Thailand, between 4100 and 1800 BP, Bentley's (2004) strontium isotopic study of population movement at Khok Phanom Di, Thailand, between 4000 and 3500 BP, and Krigbaum's studies (2003, 2005) of Neolithic subsistence patterns in Borneo. Our own stable isotopic examination of dental remains from a Da But Period (Con Co Ngua) site in Vietnam in comparison with later Metal Period dental samples from the same region (Nui Nap) is a first step in clarifying the Neolithic dietary and subsistence picture, and it provides some of the first stable isotope analyses of material from Vietnam.

\section{BACKGROUND}

\section{$\delta^{13} C$ and $\delta^{15} N$ Stable Isotopes}

Plants fall into three major metabolic groups: $\mathrm{C}_{3}, \mathrm{C}_{4}$ and CAM. Most plants (some 95\%) fall into the $\mathrm{C}_{3}$ group, including the common Southeast Asian food plants beans, tubers and rice. They fix atmospheric carbon dioxide using the enzyme rubisco to make a 3-carbon compound in the first step of the metabolic chain. Some food plants with Asian tropical climate origins fall into the $\mathrm{C}_{4}$ group, including Job's tears (Coix lacryma-jobi), some millets and sugarcane. They produce a 4-carbon compound using PEP carboxylase during the first step of photosynthesis. Finally, CAM plants such as cactus have the crassulacean acid metabolism, which improves the photosynthetic performance in water and/or carbon dioxide limited environments (Voet et al. 1999). The CAM plants are not of concern in human diet studies in Vietnam.

The heavier isotopes of elements like carbon (C) and nitrogen $(\mathrm{N})$ will be enriched in plant tissues over ambient levels during photosynthesis. $\delta^{13} \mathrm{C}$ and $\delta^{15} \mathrm{~N}$ are the indices used to express the shift of these stable isotopes relative to their respective reference standards. Calcium carbonate from the PeeDee Limestone Formation (PDB standard) is used as the ${ }^{13} \mathrm{C}$ reference standard, and atmospheric nitrogen is used as the reference standard for ${ }^{15} \mathrm{~N}$. The $\delta^{13} \mathrm{C}$ and $\delta^{15} \mathrm{~N}$ indices are defined as $\left(\mathrm{R}_{\text {sample }} / \mathrm{R}_{\text {standard }}-1\right) \times 1000$ per mil, where $\mathrm{R}_{\text {sample }}$ and $\mathrm{R}_{\text {standard }}$ are the ratios of ${ }^{13} \mathrm{C}$ to ${ }^{12} \mathrm{C}\left({ }^{15} \mathrm{~N}\right.$ to ${ }^{14} \mathrm{~N}$ for $\left.\delta^{15} \mathrm{~N}\right)$ in the sample and standard, respectively. Because of metabolic enrichment, animals that are higher in trophic level tend to have higher $\delta^{13} \mathrm{C}$ and $\delta^{15} \mathrm{~N}$ values. This is because the body retains heavier 
isotopes preferentially during normal metabolic processes. Therefore, predators have higher concentrations of ${ }^{13} \mathrm{C}$ and ${ }^{15} \mathrm{~N}$ than their prey (van der Merwe 1982).

For similar reasons, understory vegetation (typically $\mathrm{C}_{3}$ ) that is shaded is expected to have a more negative $\delta^{13} \mathrm{C}$ than vegetation that has ready access to light and atmospheric $\mathrm{CO}_{2}$, as plants in this environment will recycle more of the carbon (Jackson et al. 1993). Therefore foragers who collect from the understory of heavily forested regions would also be expected to have a more negative $\delta^{13} \mathrm{C}$ signature compared to those who forage in more open regions, and $\mathrm{C}_{3}$ consumers should have a more negative $\delta^{13} \mathrm{C}$ signature than $\mathrm{C}_{4}$ consumers.

There are two distinct groups of $\delta^{15} \mathrm{~N}$ : legumes and non-legumes. Legumes utilize both atmospheric nitrogen and ammonium ions in the soil, while non-legumes utilize only soil nitrogen. Soil nitrogen has higher $\delta^{15} \mathrm{~N}$ values than atmospheric nitrogen. As a result, non-legumes have higher $\delta^{15} \mathrm{~N}$ values than do legumes (DeNiro 1987). Marine animals have higher values for both $\delta^{13} \mathrm{C}$ and $\delta^{15} \mathrm{~N}$ than terrestrial animals because seawater is enriched in heavier isotopes compared to the atmosphere for both nitrogen and carbon dioxide, and marine life is in equilibrium with the ocean in which it resides. Because human beings will concentrate the heavier isotope from the foods we eat, the $\delta^{13} \mathrm{C}$ and $\delta^{15} \mathrm{~N}$ values in humans will be about +5 higher than the values found in the things we consume. Generally, browsing animals eat herbs, shrubs and trees (mostly $\mathrm{C}_{3}$ plants), while grazing animals will consume grasses (mostly $\mathrm{C}_{4}$ plants), and they will add their own positive metabolic shift to varying degrees with ruminants (e.g., cattle) having more positive shifts.

$\mathrm{C}$ and $\mathrm{N}$ may be obtained from any compounds that have survived in unadulterated form, but each may have slightly different $\delta^{13} \mathrm{C}$ and $\delta^{15} \mathrm{~N}$ values due to their different synthetic pathways. Because bone or tooth apatite can survive over very long time periods, it is usually the component of choice if only $\delta^{13} \mathrm{C}$ is to be measured, but it contains no nitrogen. To measure both $\delta^{13} \mathrm{C}$ and $\delta^{15} \mathrm{~N}$, collagen extracted from teeth is widely used, though it is not a single pure molecule. Because collagen's isotopic ratios are preferentially impacted by the sources of dietary protein while apatite reflects a broader spectrum of dietary carbon energy sources, both are of value even though their isotopic ratios may be impacted by both diagenesis and preparation method (Garvie-Lok et al. 2004).

If $\delta^{13} \mathrm{C}$ values from the $5000 \mathrm{BP}$ Con Co Ngua site are significantly greater than those from the 1670 BP Nui Nap Metal Period site, then people from 5000 BP may have eaten more $\mathrm{C}_{4}$ plants such as wild millet, coupled with foraging from coastal, riverine and marine foods. This would match the material culture expectations. If the $\delta^{13} \mathrm{C}$ values from the two sites are close to each other, then the Da But diet contains significant percentages of $C_{3}$ plants. Such congruence might imply plant (rice?) cultivation had been developed or transmitted here relatively early for the region, though other $\mathrm{C}_{3}$ sources are also possible.

\section{$\mathrm{Ca}, \mathrm{Ba}$ and $\mathrm{Sr}$ Ratios}

Although $\delta^{15} \mathrm{~N}$ is most useful for determining the relative contribution of marine sources to the diet, nitrogen-rich compounds such as collagen may not survive over long time periods of time. In such instances, the barium to strontium (Ba:Sr) ratio may be a useful complementary method (Burton and Price 1990), especially when coupled with other elemental methods that differentiate terrestrial and marine sources.

The solubility of $\mathrm{BaSO}_{4}$ is much less than that of $\mathrm{SrSO}_{4}$, and in seawater where there is an excess of sulfate ions compared to $\mathrm{Ba}$ and $\mathrm{Sr}$, the $\mathrm{Ba}: \mathrm{Sr}$ mass ratio equals 0.004 (Bowen 1966). However, in freshwater the concentrations of these cations are almost equal, as unpolluted freshwater does not typically contain high levels of $\mathrm{SO}_{4}{ }^{2-}$. As a result, the ratio of $\mathrm{Ba}: \mathrm{Sr}$ is close to one in terrestrial or freshwater species while in marine plants and animals the $\mathrm{Ba}: \mathrm{Sr}$ is usually $<0.1$ (Burton and Price 1990). It should be noted that the $\mathrm{Ba}: \mathrm{Sr}$ ratio is also expected to decrease as trophic level increases, as Sr better mimics calcium $(\mathrm{Ca})$. Therefore, for populations where agriculture is more developed and where it is expected to play a greater role compared to marine food sources, the $\mathrm{Ba}: \mathrm{Sr}$ ratios should be relatively higher. Both $\mathrm{Ba}$ and $\mathrm{Sr}$ may be ratioed to $\mathrm{Ca}$ to gain insights into the relative roles of trophic level and marine versus terrestrial sources in the diet, as Sr:Ca generally decreases with increasing trophic level while $\mathrm{Ba}: \mathrm{Ca}$ decreases with increasing amounts of marine food sources as well as with increasing trophic level. Thus, $\mathrm{Ba}: \mathrm{Sr}$ focuses on the marine component.

\section{SAMPLE DESCRIPTIONS}

Teeth (see Table 1) from four individuals were sampled from Nui Nap: 78NN-M10Kb, F, age 20-29, mandibular M1 with small piece of adhering mandible; 78NN-13Aka, F?, 30-39, maxillary I1, I2, M1, and M2; 78NN-MX2, F, 40-49, M2; and 76NN-M3, age and sex unknown, left mandibular M1 portion of crown only. From individual $78 \mathrm{NN}-13 \mathrm{Aka}$ four teeth were sampled to provide variation with age (generally speaking: permanent incisor crowns are complete by 3 to 4 years and erupt between 7 and 9 years; M1 crowns are completed during the $3^{\text {rd }}$ year and emerge between 6 and 7 years; M2 crowns are completed between 6 and 7 years and erupt around 12 years). Another four individuals were sampled at Con Co Ngua: 80CCN-M64, age and sex unknown, mandibular M1; 80CCN-MY, female?, adult, maxillary M1; 80CCN-M44, male, 30-39, mandibular M1; and 80CCN-M9, sex unknown, 20-29, mandibular M1.

Nui Nap is a Metal Period site with the majority of its individuals radiocarbon dated to $1670 \pm 85$ years BP with two individuals from as early as 2500 to $3000 \mathrm{BP}$. It is located $8 \mathrm{~km}$ east of present day Than Hoa about $8 \mathrm{~km}$ from the coastline (Figure 1). Situated on the side of a low limestone bluff, the site contained a variety of pottery and ceramic vessels as well as many bronze implements. The bioarchaeological and historical records suggest the inhabitants subsisted on mixed terrestrial (possibly including plant cultivation) and marine foraging. 


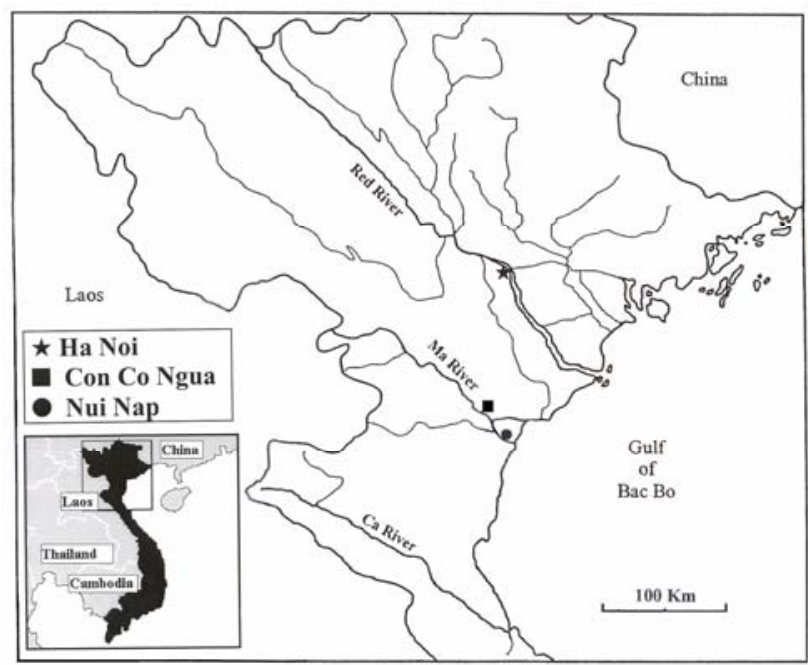

Figure 1. Sample site locations in Thanh Hoa Province, Northern Vietnam

Individuals at this site exhibit evidence of the beginnings of infectious diseases, which is consistent with the beginnings of massive population movements into the region at this time (Oxenham et al. 2005)

Con Co Ngua is a Da But (Neolithic Period) site about $30 \mathrm{~km}$ inland from the current coastline and $3.6 \mathrm{~km}$ north of the Ma River. It would have been much closer to the ocean 5000 years ago as the river has deposited significant quantities of sediment over this period. Con Co Ngua lies in a small valley surrounded by $300 \mathrm{~m}$ high limestone hills about $20 \mathrm{~km}$ north of Thanh Hoa in northern Vietnam at $20^{\circ} \mathrm{N}$ and $104^{\circ} 45^{\prime \prime} \mathrm{W}$ (Fig. 1). It consists of two pits that are thought to be temporally discontinuous with 28 burials in pit 1 and 78 burials in pit 2. Ground, polished, and flaked stone artifacts, bone implements, mat-impressed pottery fragments, and marine, riverine and estuarine remains of fish, oyster and mussels as well as bones of pig, deer, and buffalo were found at the site. The ceramic record is consistent with other sites that date to about 5000 years BP. The latter date is preferred to the clearly much too recent dates obtained from marine shell $(3020 \pm 100$ years BP) and human bone $(2740 \pm 1050$ years $\mathrm{BP})$. There is no biological evidence that agriculture or horticulture was practiced at this site, but the human assemblage suggests the inhabitants lived a sedentary life that was, overall, healthier than the average Southeast Asian populations of the period with the exception of an elevated frequency of traumatic injury (Oxenham et al. 2001; Oxenham et al. 2005).

\section{METHODS OF ANALYSIS \\ $\delta^{13} C$ and $\delta^{15} N$ Analysis}

Each tooth was first physically cleaned by removing the surface with a rotary carbide tool, followed by sonication in deionized water (18 M-ohm). The enamel covered portions of the teeth were crushed and pieces of enamel free of dentin were hand picked under a microscope (30X) for the apatite analyses. Tooth pieces that were cleaned and subsequently used for ${ }^{13} \mathrm{C} /{ }^{12} \mathrm{C}$ and elemental analyses were prepared by pulverizing them in a tungsten carbide ball mill to $<0.05 \mathrm{~mm}$. Enamel-protected dentin was similarly prepared for use in subsequent collagen analyses.

A preliminary analysis of $\mathrm{N}$ and $\mathrm{C}$ (Table 1) revealed the earlier Da But site had little detectable $\mathrm{N}$ and only 0.5 to $2 \% \mathrm{C}$ left in the enamel-protected material, indicating no useful collagen remained. The later, Metal Period samples had $1.5 \% \mathrm{~N}$ and $5 \% \mathrm{C}(9-12 \%$ collagen), suggesting they were well preserved (Stafford et al., 1988; Ambrose 1990). A number of different collagen preparation methods have been developed (Katzenberg 2000). In our case, demineralization of the samples was accomplished by soaking in $1 \mathrm{M} \mathrm{HCl}$ (trace metal grade) at $4^{\circ} \mathrm{C}$ for 3 days with gentle swirling, followed by washing with $18 \mathrm{M}$-ohm water. Lipid in the samples was removed with $2 \mathrm{~mL}$ of chloroform/methanol (3:2) (Tuross et al. 1988; Liden et al. $1995)$ followed by drying under vacuum. Collagen purity was verified by analysis of the collagen (Fig. 2) using FTIR (PE Spectrum RX 1) and by obtaining the expected $\mathrm{C}: \mathrm{N}$ ratios (Carlo Erba NC2100 combustion analyzer). Collagen samples were subsequently analyzed for $\delta^{13} \mathrm{C}$ and $\delta^{15} \mathrm{~N}$ using a stable isotope mass spectrometer (ThermoFinnegan Delta Plus) in continuous flow mode.

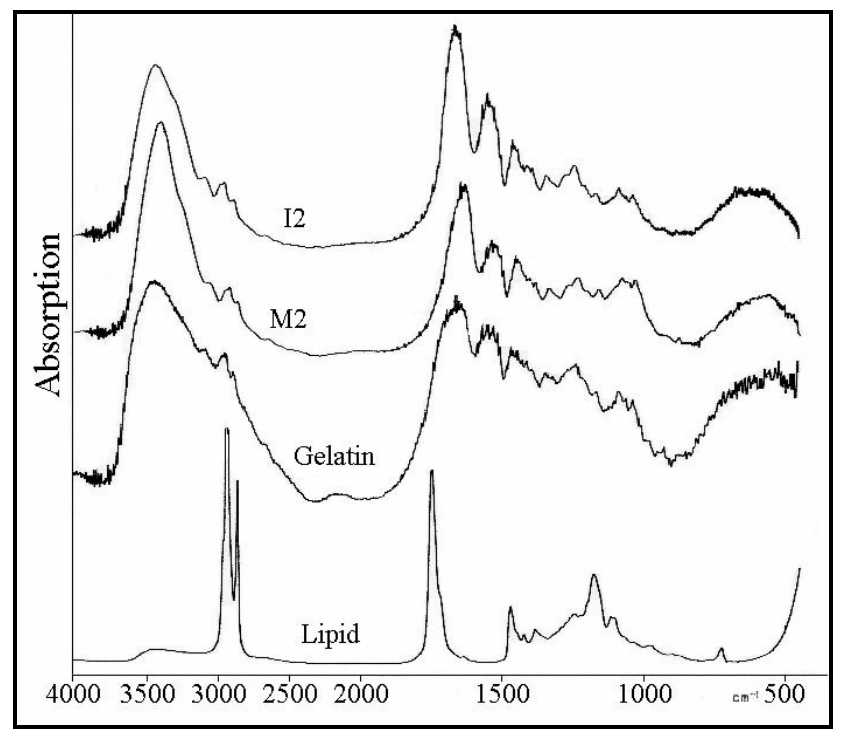

Figure 2. FTIR spectra of collagen extracted from sample 78NN13-Aka-I1 and M2 teeth, collagen (gelatin), and lipid reference samples.

Although the Da But site samples lacked enough collagen to be reliably analyzed for $\delta^{13} \mathrm{C}$ and $\delta^{15} \mathrm{~N}$, the apatite in the enamel could be analyzed for $\delta^{13} \mathrm{C}$. Following the recommendations of Koch et al. (1997), 100 mg samples of powdered tooth enamel from each site (Table 1 - all tables at end) were prepared for analysis of the inorganic, apatite carbon. Hydrogen peroxide $\left(\mathrm{H}_{2} \mathrm{O}_{2}\right)$ was used to destroy the organic matter by swirling (200 $\mathrm{rpm}$ ) the enamel powder in $5 \mathrm{~mL}$ of $30 \% \mathrm{H}_{2} \mathrm{O}_{2}$ for a day, followed by vortexing five times with $5 \mathrm{~mL}$ aliquots of 18 $\mathrm{M}$-ohm water and centrifuging (Beckman J2-HS) to 
separate a pellet from the liquid. The powders were then swirled in $5 \mathrm{~mL}$ of $1 \mathrm{M}$ acetic acid/calcium acetate buffer $(\mathrm{pH}=4.3)$ for a day to remove any carbonate contaminants. The samples were washed a final five times with 18 $\mathrm{M}$-ohm water and dried at $40^{\circ} \mathrm{C}$ followed by analysis of their $\delta^{13} \mathrm{C}$ as described above. The enamel powders were analyzed by thermogravimetry (Shimadzu TGA-50) and X-ray diffraction (Philips PW1830/1710 XRD) before and after cleaning to check for residual contamination or alteration and to estimate crystallite sizes using the [002] peak at $26^{\circ}(2 \theta)$.

\section{Elemental Analyses}

Because diagenetic alteration of $\mathrm{Ba}$ and $\mathrm{Sr}$ can be significant, care must be exercised in preparing samples and in interpreting results (Burton et al. 1999). Samples $(100 \mathrm{mg})$ of powdered enamel were placed in virgin polyethylene vials and cleaned with $1 \mathrm{M}$ acetic acid/ calcium acetate buffer and washed as described above. The enamel was analyzed for calcium $(\mathrm{Ca})$ and trace elements such as uranium (U) before and after cleaning by x-ray fluorescence (Philips PANalytical Epsilon 5 XRF) to monitor the efficacy of the cleaning procedure. Cleaned samples were dissolved with trace metal grade nitric acid (Fisher) and analyzed by ICP-OES (Thermo-Jarrell Ash Atomscan 16) to obtain adequate detection limits for the trace metals of interest.

\section{RESULTS AND DISCUSSION}

\section{Integrity of Samples}

The relative standard deviation of the $\% \mathrm{~N}$ and $\% \mathrm{C}$ (Table 1) between individuals is comparable to that found within one individual's teeth (78NN13Aka-incisor 1 and 2, right molar 1 and 2). This individual exhibits slightly better preservation in the molars than the incisors, as expected. The mandible fragment and the loose crown fragment (76NNM3) both had very poor preservation for the period and they were different tissue types than the enamel-protected material used for the remaining analyses so they are excluded from the rest of this discussion.

The cleaning procedure lowered Fe, Mn, and $\mathrm{U}$ to 69 , 25, and 0 ppm, respectively, in the Da But samples. These levels are near modern enamel values (Kohn et al. 1999) and are slightly higher than in the Metal Period samples $(35,8$, and $0 \mathrm{ppm})$. No contamination or any alteration products after cleaning were observed using XRD (Fig. 3). The XRD spectra and crystallite sizes are comparable to enamel data from recent human skeletons (data not shown). The [002] FWHM (full width at half maximum) were not significantly different $(P=0.46)$ between the two sites (Table 2), and relative peak height data (not shown) are consistent with archaic human apatites reported by Koch et al. (1997).

\section{Elemental Analyses}

The logs of the ratios of $\mathrm{Ba}: \mathrm{Sr}$ for the tooth samples from $5000 \mathrm{BP}$ are significantly lower (two-group t-test, $P<$ 0.001 ) than those from 2000 BP (Table 3). Thus, people from $5000 \mathrm{BP}$ appear to have had greater percentages of marine foods in their diet than people from $2000 \mathrm{BP}$. This interpretation is supported by the somewhat higher levels of Cu (8 versus $6 \mathrm{ppm}, P=0.31)$ and lower levels of $\mathrm{Zn}(65$ versus $123 \mathrm{ppm}, P=0.07)$ found at Con Co Ngua compared to Nui Nap using ICP-OES. Similar levels (10.5 versus $6.8 \mathrm{ppm}$ for $\mathrm{Cu}$, and 97.2 versus $104.6 \mathrm{ppm}$ for $\mathrm{Zn}$ ) were found in pre-Hispanic Canary Island populations with respectively higher and lower amounts of marine food in their diet (González-Reimers et al., 2001). The trend for the individual with multiple teeth analyzed also suggests that marine sources played an increasing role with age.

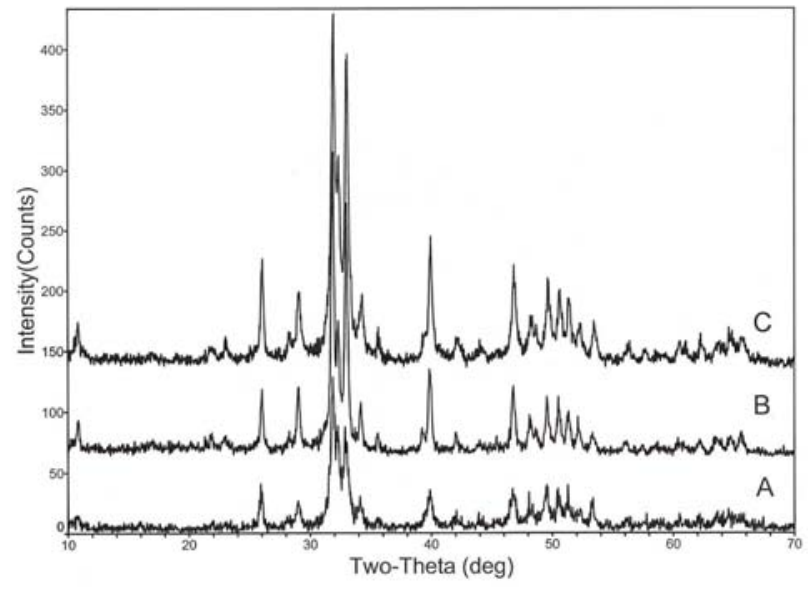

Figure 3. XRD spectra of tooth enamels for (A) Da But CCN-M64 before cleaning; (B) Metal Period NN-Akal3-I2 before cleaning; and (C) Metal Period NN-Aka13-M2 after cleaning.

\section{$\delta^{13} C$ and $\delta^{15} N$}

The $\delta^{13} \mathrm{C}$ values for apatite $(-16.54 \pm 0.42 \%)$ were significantly lower (two-group t-test, $P<0.001$ ) than the collagen values $(-19.77 \pm 0.58 \%$ ) for the Metal Period site. Collagen tracks the dietary protein sources while apatite follows the whole diet. In addition, collagen from dentin will reflect a later period in the individual's life than apatite from tooth enamel. A comparison with the stable isotope data from Lee-Thorp et al. (1989) suggests these Metal Period individuals probably obtained their dietary energy primarily from $\mathrm{C}_{3}$ sources, and their protein from either marine or $\mathrm{C}_{3}$ sources. Temporal $( \pm 1 \%$ ) and spatial $( \pm 1.5 \%)$ variations in the sources can blur these distinctions (Heaton, 1999). Jim et al. (2004) conducted controlled feeding studies with rats and the data presented here best fits a $\mathrm{C}_{3}$ protein source coupled with a $\mathrm{C}_{3}$ energy source based on their findings. This conclusion is further supported by the $\delta^{15} \mathrm{~N}(10.20 \pm 0.34 \%$ o data, as this value fits primarily with a terrestrial source of protein $(6-10 \%)$, albeit on the marine end of that continuum. Chisholm and Koike (1996) have obtained $\delta^{15} \mathrm{~N}$ and $\delta^{13} \mathrm{C}$ values from inland and coastal sites for Japanese dating to the Jomon and Yayoi Periods, and a comparison of our Nui Nap, Metal Period collagen data with their values fits best with an inland site where rice cultivation has been well established and where marine resources are present but play a minor role. 
A two-group t-test of the apatite $\delta^{13} \mathrm{C}$ values (Table 2) indicates the Da But site $(-14.5 \pm 0.6 \%)$ has significantly higher $(P<0.001) \delta^{13} \mathrm{C}$ than the Metal Period site $(-16.54$ $\pm 0.42 \%$ ). The $\delta^{13} \mathrm{C}$ alone does not tell us whether this difference is due to an increased use of marine sources, to a greater use of plants from more open areas, or to a greater use of $\mathrm{C}_{4}$ plant sources. However, a plot of the $\mathrm{Ba}: \mathrm{Sr}$ ratio versus the $\delta^{13} \mathrm{C}$ values (Fig. 4) suggests that some of the dietary difference is due to a greater use of marine sources at Con Co Ngua. The average of the apatite $\delta^{13} \mathrm{C}$ values for Con Co Ngua are more negative than the $-13.2 \pm 0.8 \%$ o reported for a coastal Neolithic site (Niah Cave, median age $3080 \mathrm{BP}$ ) in Borneo (Krigbaum 2005), but are equal to values $(-14.4 \pm 0.19 \%$ ) for their inland, late Neolithic/Metal Period site (Lubang Angin, median age 1960 BP) . This may indicate a lesser reliance on marine sources or a lesser use of $\mathrm{C}_{4}$ plants (such as sugarcane) than at the coastal site in Borneo, or that the $\mathrm{C}_{3}$ plant, rice, was beginning to play a role in the diet at Con Co Ngua.

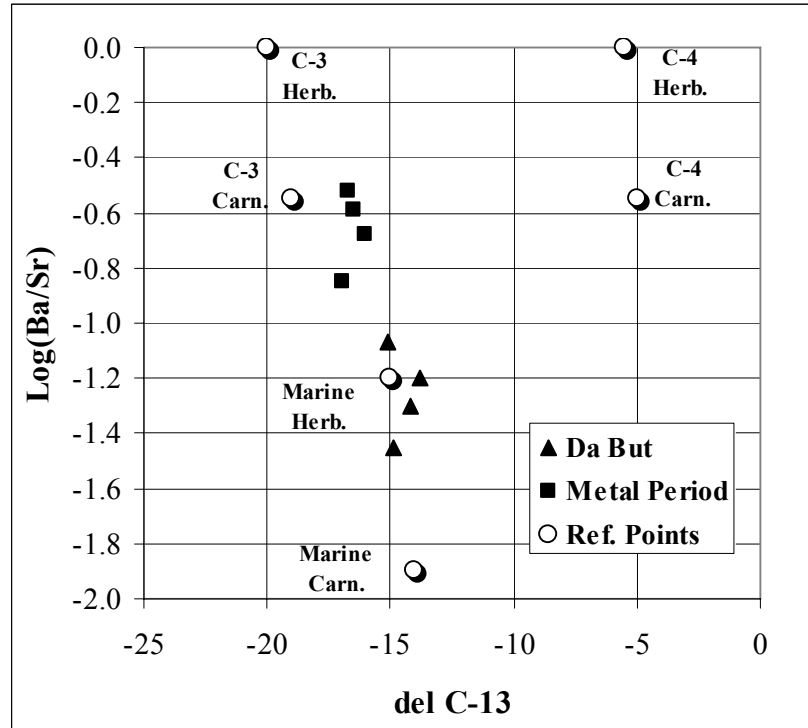

Figure 3. Comparison of Da But and Metal Period sites using apatite $\delta^{13} C$ and $B a / S r$ ratios. Average values for $C-3, C-4$, and marine herbivores and carnivores are also plotted. (Data for the reference points are based on DeNiro (1987) and Burton and Price (1990).)

\section{CONCLUSIONS}

While the preliminary nature of these results and the small sample sizes need to be considered, some interesting results have been found that will form testable hypotheses for future isotopic work in Vietnam. The people at Nui Nap appear to have relied heavily on $\mathrm{C}_{3}$ plants (probably rice) with less use of marine sources than people from the earlier Da But, Con Co Ngua site. This is consistent with expectations that agriculture was well established in the Metal Period. Intriguingly, while the Da But diet contained significant marine foodstuffs, there was also more of a $\mathrm{C}_{3}$ component compared to values found for an earlier Neolithic site in Borneo. This suggests that rice may have begun to play a role in the mid-Holocene diet in northern
Vietnam, though other $\mathrm{C}_{3}$ plants were also consumed. At present there is a lack of archaeological evidence for rice cultivation between 5,000 and 6,000 years BP in northern Vietnam. Future work will focus on clarifying this issue.

\section{ACKNOWLEDGMENTS}

We thank the Colorado College Natural Science Division and the McKee Family Trust for funding, and instrumentation used in this study was purchased through grants from the Margaret and Otis Barnes Trust and the Fairchild and National Science Foundations (ILI-9352208).

\section{REFERENCES}

Ambrose S. H. 1990. Preparation and characterization of bone and tooth collagen for isotopic analysis. Journal of Archaeological Science 17: 431-451.

Bentley R.A. 2004. Characterising human mobility by strontium analysis of the skeletons. In Higham C.F.W. and Thosarat R. eds. The Excavation of Khok Phanom Di: a Prehistoric Site in Central Thailand Volume VII: Summary and Conclusions, pp. 169-166. London: Society of Antiquities.

Bowen H. 1966. Trace Elements in Biochemistry. New York: Academic Press.

Bui Vinh 1991. The Da But Culture in the Stone Age of Vietnam. Bulletin of the Indo-Pacific Prehistory Association 10: 127-131.

Burton J. and Price T. 1990. The ratio of barium to strontium as a paleodietary indicator of consumption of marine resources. Journal of Archaeological Science 17: 547-557.

Burton J.H., Price T.D. and Middleton W.D. 1999. Correlation of bone $\mathrm{Ba} / \mathrm{Ca}$ and $\mathrm{Sr} / \mathrm{Ca}$ to biological purification of calcium. Journal of Archaeological Science 26: 609-616.

Chisholm B. and Koike H. 1996. Reconstructing prehistoric Japanese diet using stable isotopic analysis. In Omoto K. ed. Interdisciplinary Perspectives on the Origins of the Japanese, pp 199-222. International Research Center for Japanese Studies Kyoto.

DeNiro M. 1987. Stable isotopy and archaeology. American Scientist 75: 182-191.

Garvie-Lok S.J., Varney T.L. and Katzenberg M.A. 2004. Preparation of bone carbonate for stable isotope analysis: the effects of treatment time and acid concentration. Journal of Archaeological Science 31: 763-776.

González-Reimers E., Velasco-Vásquez J., Arnay-de-la-Rosa M., Santolaria-Fernández F. and Galindo-Martín L. 2001. Palenutritional analysis of the pre-Hispanic population from Fuerteventura Canary Islands. The Science of the Total Environment 264: 215-220.

Heaton T.H.E. 1999. Spatial species and temporal variations in the ${ }^{13} \mathrm{C} /{ }^{12} \mathrm{C}$ ratios of $\mathrm{C}_{3}$ plants: implications for palaeodiet studies. Journal of Archaeological Science 26: 637-649.

Higham C.F.W. 1989. The Archaeology of Mainland Southeast Asia. Cambridge: Cambridge University Press.

Jackson P.C., Meinzer F.C., Goldstein G., Holbrook N.M., Cavlier J. and Rada F. 1993. Environmental and physiological influences on carbon isotope composition of gap and understory plants in a lowland tropical forest. In Ehleringer J.R. Hall A.E. and Farquhar G.D. eds. Stable 
Isotopes and Plant Carbon-Water Relations, pp. 131-140. San Diego: Academic Press.

Jim S., Ambrose S.H. and Evershed R.P. 2004. Stable carbon isotopic evidence for differences in the dietary origin of bone cholesterol collagen and apatite: implications for their use in paleodietary reconstruction. Geochimica et Cosmochimica Acta 68: 61-72.

Katzenberg M.A. 2000. Stable isotope analysis: A tool for studying past diet demography and life history. In Katzenberg M.A. and Saunders S.R. eds. Biological Anthropology of the Human Skeleton, pp. 305-327. New York: Wiley-Liss.

King C.A. and Norr L. 2006. Palaeodietary change among pre-State Metal-Age societies in Northeast Thailand: a study using bone stable isotopes. In Oxenham M. and Tayles N. eds. Bioarchaeology of Southeast Asia, pp. 241-62. Cambridge: Cambridge University Press.

Koch P.L., Tuross N., and Fogel M. L. 1997. The effects of sample treatment and diagenesis on the isotopic integrity of carbonate in biogenic hydroxylapatite. Journal of Archaeological Science 24: 417-429.

Kohn M.J., Schoeninger M.J. and Barker W.W. 1999. Altered states: Effects of diagenesis on fossil tooth chemistry. Geochimica et Cosmochimica Acta 63: 2737-2747.

Krigbaum J. 2003. Neolithic subsistence patterns in northern Borneo reconstructed with stable carbon isotopes of enamel. Journal of Anthropological Archaeology 22: 292-304.

Krigbaum J. 2005. Reconstructing human subsistence in the west mouth Niah Cave Sarawak burial sites using stable isotopes of carbon. Asian Perspective 44: 73-89.
Lee-Thorp J.A., Sealy J.C. and van der Merwe N.J. 1989. Stable carbon isotope ratio differences between bone collagen and bone apatite and their relationship to diet. Journal of Archaeological Science 16: 585-599.

Liden K., Takahashi C. and Nelson D.E. 1995 The effects of lipids in stable isotope analysis and the effects of $\mathrm{NaOH}$ treatment on the composition of extracted bone collagen. Journal of Archaeological Science 22: 321-326.

Nguyen K.S. 1997. In the framework of the maritime culture of Vietnam: the prehistoric maritime culture of the northeast. Vietnamese Studies 1231: 87-116.

Oxenham M.F., Walters I., Nguyen L.C. and Nguyen K.T. 2001. Case studies in ancient trauma: mid-Holocene through Metal Periods in northern Viet Nam. In Henneberg M. and Kilgariff J. eds. The Causes and Effects of Biological Variation, pp. 83-102. Adelaide: Australasian Society for Human Biology, University of Adelaide.

Oxenham M.F., Nguyen K.T. and Nguyen L.C. 2005. Skeletal evidence for the emergence of infectious disease in bronze and iron age northern Vietnam. American Journal of Physical Anthropology 126: 359-376.

Stafford T.W. Jr. Brendel K. and Duhamel R. 1988. Radiocarbon ${ }^{13} \mathrm{C}$ and ${ }^{15} \mathrm{~N}$ analysis of fossil bone: removal of humates with XAD-2 resin. Geochimica Cosmochimica Acta 52: 2257-2267.

Tuross N., Fogel M.L. and Hare P. E. 1988. Variability in the preservation of the isotopic composition of collagen from fossil bone. Geochimica et Cosmochimica Acta 52: 929-935.

van der Merwe N.J. 1982. Carbon isotopes photosynthesis and archaeology. American Scientist 70: 596-606.

Voet D., Voet J.G. and Pratt C. W. 1999. Fundamentals of Biochemistry. New York: John Wiley and Sons.

Table 1. Initial determination of organic and inorganic carbon and nitrogen.

\begin{tabular}{lllll}
\hline Sample & $\begin{array}{l}\text { \% Carbon } \\
\text { (Total) }\end{array}$ & $\begin{array}{l}\text { \% Nitrogen } \\
\text { (Total) }\end{array}$ & $\begin{array}{l}\text { Weight \% } \\
\text { Collagen }\end{array}$ & $\begin{array}{l}\text { Non-Collagen } \\
\text { \% Carbon }\end{array}$ \\
\hline Nui Nap ( 2000 BP) & & & & \\
78NN13-Aka-I1 & 5.80 & 1.53 & 9.5 & 2.53 \\
78NN13-Aka-I2 & 5.82 & 1.48 & 9.2 & 2.65 \\
78NN13-Aka-RM1 & 6.62 & 1.79 & 11.2 & 2.75 \\
78NN13-Aka-RM2 & 7.26 & 1.86 & 11.6 & 3.26 \\
78NNM-10KB-LM1 & 5.52 & 1.40 & 8.7 & 2.52 \\
10KB (Jaw Bone) & 1.90 & 0.17 & 1.1 & 1.52 \\
78NN-MX2-LM2 & 5.54 & 1.31 & 8.2 & 2.71 \\
76NN-M3-LM1-frag & 0.80 & $\leq 0.072$ & $\leq 0.5$ & $\geq 0.63$ \\
Con Co Ngua ( 5000 BP) & & & & $\geq 0.60$ \\
80CCN-M64-LM1 & 0.64 & $\leq 0.019$ & $\leq 0.1$ & $\geq 0.77$ \\
80CCN-MY-RM1 & 0.95 & $\leq 0.082$ & $\leq 0.5$ & $\geq 0.50$ \\
80CCN-M44-LM1 & 0.58 & $\leq 0.035$ & $\leq 0.22$ & $\geq 0.52$ \\
80CCN-M9-LM1 & 0.60 & $\leq 0.039$ & $\leq 0.24$ & \\
\hline
\end{tabular}

The amount of collagen was estimated from $\%$ Collagen $=(\%$ of Nitrogen $) * 6.25$.

${ }^{\mathrm{b}}$ Inorganic carbon was estimated from Total \% C - (\% Collagen/2.90). 
Table 2. Results of $\delta 13 \mathrm{C}$ and $\delta^{15} \mathrm{~N}$ analysis of collagen and apatite, and $\mathrm{Ba} / \mathrm{Sr}$ data for apatite. Instrumental variation was $\leq \mathbf{0 . 1 \%}$, and replicate analyses of the same tooth were $\leq \mathbf{0 . 3 \%}$ for the isotopic data, and $\leq \mathbf{0 . 1 0}$ in the $\log$ (ratio).

\begin{tabular}{|c|c|c|c|c|c|c|c|}
\hline \multirow[t]{2}{*}{ Sample } & \multicolumn{4}{|c|}{ Collagen } & \multicolumn{2}{|c|}{ Apatite } & \multirow{2}{*}{$\begin{array}{l}\text { Crystallite } \\
\text { FWHM } \\
{[002]}\end{array}$} \\
\hline & $\delta 15 N(\%)$ & Wt. \% N & $\delta 13 C(\%)$ & Wt. \% C & $\delta 13 C(\%)$ & Wt.\% C & \\
\hline \multicolumn{8}{|l|}{ Nui Nap $(\sim 2000$ BP) } \\
\hline 78NN13-Aka-I1 & 10.8 & 16.58 & -19.3 & 45.25 & -16.5 & 0.66 & 0.3 \\
\hline 78NN13-Aka-I2 & 9.4 & 15.91 & -20.5 & 44.31 & & 0.6 & 0.24 \\
\hline 78NN13-Aka-M1 & 9.9 & 14.64 & -20.5 & 40.38 & -16.7 & 0.72 & 0.34 \\
\hline 78NN13-Aka-M2 & 9.8 & 16.12 & -20.5 & 43.45 & & 0.75 & 0.24 \\
\hline 78NN13-10KB-M1 & 10.6 & 15.94 & -19.1 & 43.72 & -17 & 0.85 & 0.3 \\
\hline NNMX2 & 10 & 16.11 & -20.1 & 43.94 & -16 & 0.74 & 0.33 \\
\hline Avg & 10.2 & 15.92 & -19.77 & 43.66 & -16.54 & 0.72 & 0.29 \\
\hline St Dev & 0.34 & 0.2 & 0.58 & 0.32 & 0.42 & 0.08 & 0.04 \\
\hline \multicolumn{8}{|c|}{ Con Co Ngua ( 5000 BP) } \\
\hline 80CCN-M64-LM1/2 & & & & & -13.8 & 0.57 & 0.35 \\
\hline 80CCN-MY-RM1 & & & & & -15.1 & 0.84 & 0.28 \\
\hline 80CCN-M44-LM1 & & & & & -14.9 & 0.89 & 0.34 \\
\hline 80CCN-M9-LM1 & & & & & -14.2 & 0.73 & 0.28 \\
\hline Avg & & & & & -14.5 & 0.76 & 0.31 \\
\hline St Dev & & & & & 0.61 & 0.14 & 0.04 \\
\hline
\end{tabular}

Table 3. Results of elemental analyses using ICP-OES (Ba, $\mathrm{Cu}, \mathrm{Sr}$, and $\mathrm{Zn}$ in ppm) and XRF (Ca in \%).

\begin{tabular}{lllllll}
\hline Sample Origin & \multicolumn{7}{c}{ Element } & Log \\
\hline Nui Nap ( 2000 BP) & $\mathrm{Ca}$ & $\mathrm{Ba}$ & $\mathrm{Cu}$ & $\mathrm{Sr}$ & $\mathrm{Zn}$ & $\mathrm{Ba} / \mathrm{Sr}$ \\
78NN13-Aka-I1 & 26.12 & 32 & 6 & 124 & 116 & -0.59 \\
78NN13-Aka-I2 & 26.03 & 30 & 5 & 136 & 110 & -0.66 \\
78NN13-Aka-M1 & 25.34 & 32 & 6 & 105 & 139 & -0.52 \\
78NN13-Aka-M2 & 25.85 & 20 & 11 & 126 & 102 & -0.80 \\
78NN13-10KB-M1 & 26.53 & 18 & 7 & 123 & 144 & -0.85 \\
NNMX2 & 25.99 & 27 & 3 & 129 & 124 & -0.68 \\
Avg & 25.98 & 26 & 6 & 124 & 123 & -1 \\
St Dev & 0.39 & 6 & 3 & 11 & 16 & 0 \\
Con Co Ngua ( $\mathbf{5 0 0 0}$ BP) & & & & & & \\
80CCN-M64-LM1/2 & 26.03 & 7 & 4 & 112 & 29 & -1.20 \\
80CCN-MY-RM1 & 26.63 & 11 & 13 & 133 & 51 & -1.07 \\
80CCN-M44-LM1 & 23.47 & 12 & 9 & 336 & 57 & -1.45 \\
80CCN-M9-LM1 & 25.71 & 23 & 8 & 466 & 122 & -1.30 \\
Avg & 25.46 & 13 & 8 & 262 & 65 & -1.25 \\
St Dev & 1.38 & 7 & 4 & 169 & 40 & 0.16 \\
\hline
\end{tabular}

